This item was submitted to Loughborough's Research Repository by the author.

Items in Figshare are protected by copyright, with all rights reserved, unless otherwise indicated.

\title{
Special issue on plenary and invited papers from ICOPS 2009
}

PLEASE CITE THE PUBLISHED VERSION

PUBLISHER

(C) IEEE

VERSION

VoR (Version of Record)

LICENCE

CC BY-NC-ND 4.0

REPOSITORY RECORD

Beg, Farhat N., Michael G. Kong, and Monica Blank. 2019. "Special Issue on Plenary and Invited Papers from ICOPS 2009”. figshare. https://hdl.handle.net/2134/6139. 
This item was submitted to Loughborough's Institutional Repository (https://dspace.lboro.ac.uk/) by the author and is made available under the following Creative Commons Licence conditions.

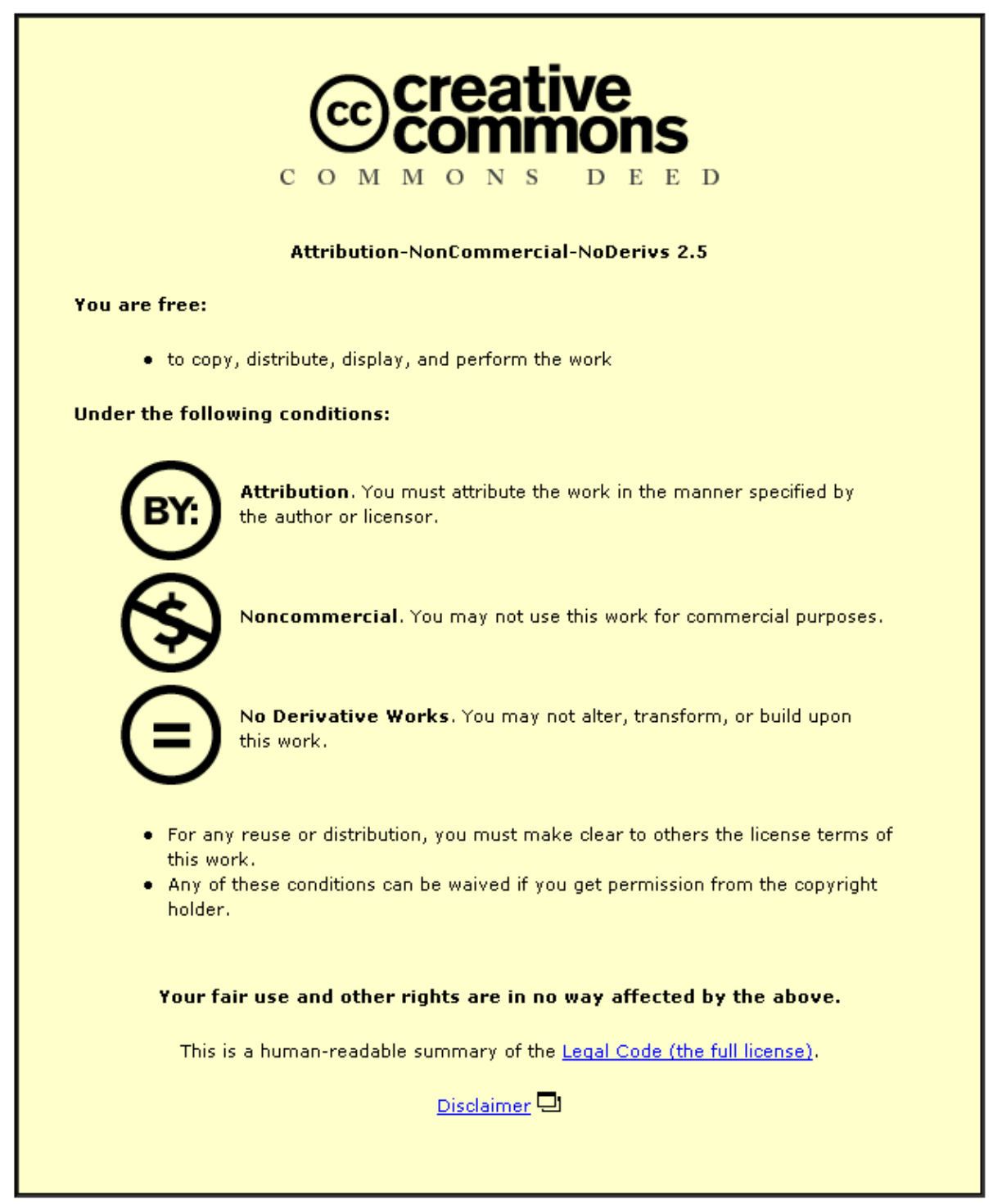

For the full text of this licence, please go to: http://creativecommons.org/licenses/by-nc-nd/2.5/ 


\section{Special Issue on Plenary and Invited Papers From ICOPS 2009}

$\mathbf{T}$ HE 36th IEEE International Conference on Plasma Science (ICOPS) and the 23rd Symposium on Fusion Engineering (SOFE) were jointly held in San Diego, CA, from May 31 to June 5, 2009. It was the very first time that ICOPS and SOFE had a joint technical program, providing an excellent opportunity to combine the typically diverse topics of ICOPS with the focus on fusion systems and engineering of SOFE. The technical program included three joint ICOPS/SOFE plenary talks and three ICOPS plenary talks. In addition, there were 222 oral and 314 poster ICOPS specific presentations. Three joint ICOPS/SOFE plenary talks were given by Dr. Guenter Janeschitz (ITER IO), Dr. John Sethian (NRL), and Dr. Ed Moses (LLNL), whereas three ICOPS plenary talks were given by Dr. Michael Kong (Loughborough University, U.K.), Dr. Mark Herrmann (Sandia National Laboratory), and Dr. Bob Barker (Air Force Office of the Scientific Research). The presented research work showcased the latest progress in many different plasma areas including low-temperature plasmas, thermal plasmas, electron beam plasmas, laser plasmas, space plasmas, complex plasmas, and fusion plasmas. Collectively, they represent a vast diversity from intriguing nanoscale plasmas formed at the tip of a nanostructure, through very large scale fusion systems including ITER, to space plasmas. Impacts of these diverse plasma systems are also wide ranging from energy, coherent light sources and flat-panel display, coating, surface modification, and microscopic fabrication to medicine and biology. This special issue represents a small collection of some of the most exciting presentations from ICOPS.

We would like to thank all the authors who submitted their papers to this issue. Our gratitude goes to the referees of this issue for their timely, meticulous, and constructive reports that helped improve the papers. Our special appreciation goes to Editor-in-Chief Dr. S. Gitomer and Assistant Publication Peer Review Support Specialist Sean Gillispe of the IEEE TRANSACTIONS ON Plasma SCIENCE for their guidance, assistance, and patience.

\section{FARHAT N. BEG, Guest Editor}

Department of Mechanical and Aerospace Engineering University of California San Diego

La Jolla, CA 92093 USA

Michael G. Kong, Guest Editor

Centre for Biological Engineering,

Department of Electronic and Electrical Engineering

Loughborough University

LE11 3TU Leicestershire, U.K.

Monica Blank, Guest Editor

Communications and Power Industries

Palo Alto, CA 94304 USA

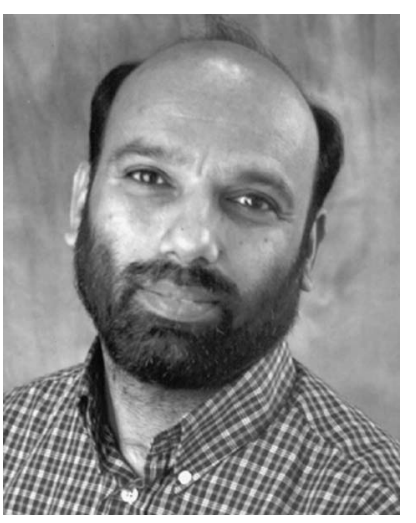

Farhat N. Beg (M'97-SM'09) received the M.Sc. and M.Phil. degrees in physics from Quaidi-Azam University, Islamabad, Pakistan, and the Ph.D. degree in plasma physics from Imperial College London, London, U.K., in 1995.

He was a Research Associate and then a Research Fellow with Imperial College London. In 2003, he joined the faculty of the University of California San Diego, La Jolla, where he is currently a Professor of Engineering Physics with the Department of Mechanical and Aerospace Engineering, conducting research in the field of high-intensity short-pulse laser-matter interactions, wire array $Z$-pinches, and $X$-pinches. He is also a Visiting Professor with Imperial College London. He has published well over 100 articles in peer-reviewed journals.

Dr. Beg has been a Technical Area Coordinator to a number of International Conferences on Plasma Science (ICOPS) and was the General Chair of ICOPS held in June 2009 in San Diego. $\mathrm{He}$ is the recipient of the IEEE NPSS Early Achievement Award. He is a Fellow of the American Physical Society. 

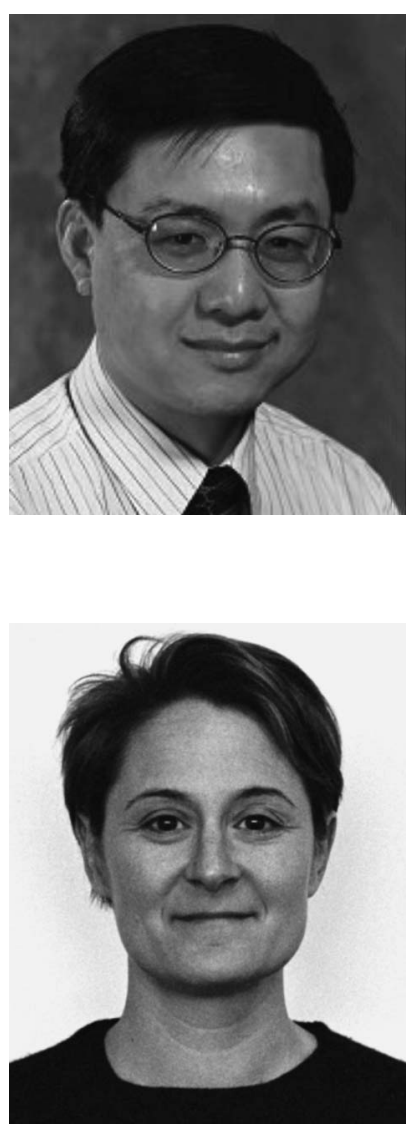

Monica Blank (M'95) received the B.S. degree in electrical engineering from the Catholic University of America, Washington, DC, in 1988 and the M.S. and Ph.D. degrees in electrical engineering from the Massachusetts Institute of Technology, Cambridge, in 1991 and 1994, respectively.

In 1994, she joined the Vacuum Electronics Branch, Naval Research Laboratory, Washington, where she was responsible for the design and demonstration of high-power millimeter-wave vacuum electronic devices for radar applications. In 1999, she joined the Gyrotron Team, Communications and Power Industries (formerly Varian), Palo Alto, CA, where she continues her work on high-power millimeter-wave and terahertz gyrotron amplifiers and oscillators for fusion, radar, industrial, and NMR applications.

Dr. Blank has been the recipient of several professional awards, including the 1998 Alan Berman Publication Award at the Naval Research Laboratory and the Robert L. Woods Award for Excellence Vacuum Electronics Technology in 1999. She has previously served on the IEEE Plasma Science and Applications Executive Committee and is currently a Senior Editor for the IEEE TRANSACTIONS ON Plasma SCIENCE.

Michael G. Kong (M'94-SM'98) received the B.Sc. and M.Sc. degrees in electronics from Zhejiang University, Hangzhou, China, and the Ph.D. degree in electrical engineering from the University of Liverpool, Liverpool, U.K.

the University of Liverpool, he joined Loughborough University, Leicestershire, U.K., in 1999, where he is currently the Chair of bioelectrical engineering with the Department of Electronic research interests include nonthermal atmospheric discharges and pulsed electromagnetic fields, as well as their applications to medicine and biology. He has published over 100 journal papers, some 50 plenary/invited conference talks, and more than 130 conference presentations.

Dr. Kong has been a Guest Editor for the IEEE TRANSACTIONS ON PLASMA SCIENCE, Plasma Sources Science and Technology. 